Article

\title{
Heteroaromatic Polyamides with Improved Thermal and Mechanical Properties
}

\author{
Miriam Trigo-López*® Ana M. Sanjuán, Aranzazu Mendía, Asunción Muñoz®, \\ Félix C. García $\mathbb{D}$ and José M. García * ${ }^{\mathbb{D}}$ \\ Departamento de Química, Facultad de Ciencias, Universidad de Burgos, Plaza de Misael Bañuelos s/n, \\ 09001 Burgos, Spain; amsanjuan@ubu.es (A.M.S.); amendia@ubu.es (A.M.); amugnoz@ubu.es (A.M.); \\ fegarcia@ubu.es (F.C.G.) \\ * Correspondence: mtrigo@ubu.es (M.T.-L.); jmiguel@ubu.es (J.M.G.)
}

Received: 10 July 2020; Accepted: 8 August 2020; Published: 10 August 2020

check for updates

\begin{abstract}
We prepared high-performance aromatic copolyamides, containing bithiazole and thiazolo-thiazole groups in their main chain, from aromatic diamines and isophthaloyl chloride, to further improve the prominent thermal behavior and exceptional mechanical properties of commercial aramid fibers. The introduction of these groups leads to aramids with improved strength and moduli compared to commercial meta-oriented aromatic polyamides, together with an increase of their thermal performance. Moreover, their solubility, water uptake, and optical properties were evaluated in this work.
\end{abstract}

Keywords: aromatic polyamides; aramid; improved properties; mechanical properties; thermal properties; high-performance polymers

\section{Introduction}

Polymers belong to a high-performance family when they have a few outstanding properties and characteristics, and usually need to have, at least, exceptional mechanical and thermal behavior. Aromatic polyamides, usually known in the field with the shorten name aramids, are a representative member of this family because they have specific moduli and strength that outperform conventional materials, such as glass or steel, especially considering their much lower density. Such properties derive from the aromatic nature of the polymer main chain that contains a minimum of $85 \%$ of the amide groups directly linked to two aromatic rings, resulting in high chain rigidity and efficient hydrogen bonding (high cohesive energy) [1]. As a result, these materials are used as fibers to prepare innovative protecting materials [2] and composites [3,4]. The marketed aramids include, the meta-oriented $\operatorname{poly}(m$-phenylene isophthalamide), the para-oriented poly(p-phenyleneterephthalamide), and the meta and para-oriented copolymer copoly ( $p$-phenylene/3, $4^{\prime}$-diphenylether terephthalamide).

Research efforts in the field are oriented in three directions, being the improvement of the properties of marketed aromatic polyamide fibers, or by fully design of the chemical structure to offer innovative properties, or even both, mainly by maintaining the chemical structure, but introducing functionality by copolymerizing conventional monomers with synthetic ones [2]. Herewith, we have followed the third approach by preparing thermally and mechanically improved copolyamides.

The following has to be considered and taken into account to face the improvement of the properties of marketed aromatic polyamides. They show high thermal resistance and keep their mechanical properties even at high temperatures [5] with decomposition temperatures above 400 and $500{ }^{\circ} \mathrm{C}$ for meta- and para-aramids, respectively, as a result of the high bond dissociation energies of $\mathrm{C}-\mathrm{N}$ and $\mathrm{C}-\mathrm{C}$ bonds. Also, due to their hydrogen bonding and polymer backbone rigidity, 
the $T_{\mathrm{g}}$ values are between 272 and $275{ }^{\circ} \mathrm{C}$ for poly $\left(m\right.$-phenylene isophthalamide) and $295{ }^{\circ} \mathrm{C}$ for poly( $p$-phenyleneterephthalamide) [6].

Another unique property of commercial aramids, related to their thermal stability, is their low flammability, measured by the LOI (limiting oxygen index). The value for aromatic polyamides is $30-32 \%$ and $28-30 \%$ for meta- and para-aramids, respectively. Polymers with flame retardant properties commonly have halogens in their formulation [7-10].

On the other hand, the introduction of heterocyclic rings in the main chain of aromatic polyamides is known to provide excellent thermal stabilities to the polymers and improve their solubility. Recent advances in this sense include the introduction of phenyl-1,3,5-triazine, or the incorporation of planar dibenzofuran moieties in the polymer backbone, which resulted in polymers high $T_{\mathrm{g}} \mathrm{s}$ and excellent thermal stabilities [11,12].

In relation to the mechanical properties, recent efforts towards their improvement include the use of phthalazinone moieties [13], fluorine-containing monomers [6,14], cyano groups [15], bulky xanthene groups [8] or 4-aryl-2,6-diphenylpyridine moieties [16], in the polymer structure. The crosslinking of polymeric chains in aramids leads to polymers with improved thermal and mechanical properties, as demonstrated in some works $[17,18]$. Aromatic bithiazoles are well-studied compounds and are commonly used, regarding their biological properties, as antivirals against hepatitis B or HIV [19,20], and also in polymers as fluorescent chemosensors, and in polymer complexes with magnetic behavior [21], and in photovoltaics and thin-film transistors [22-24]. Also, thiazolo [4,5-d]thiazoles are recently studied as new domains for semiconductors and potential optoelectronic applications, showing intramolecular charge transfer $[25,26]$. Moreover, the intermolecular interactions between $\mathrm{S}$ and $\mathrm{N}$ atoms are relevant in incrementing the interchain interactions increasing the cohesive energy and, accordingly, in the thermal and mechanical performance of polymers having this group in their main chain [27].

\section{Experimental Procedures}

\subsection{Materials}

We used the chemicals and solvents without further purification unless indicated. 4-nitrobenzaldehyde (for synthesis, Merck, Darmstadt, Germany), 4-nitroacetophenone (98\%, Alfa Aesar, Kandel, Germany), $\mathrm{Br}_{2}$ (99.8\%, Alfa Aesar), dithiooxamide (98\%, Alfa Aesar), sulfuric acid (95\%, VWR-Prolabo, Fonteney-sous-bois, France) diethyl ether (VWR-Prolabo), ethanol (99.9\%, VWR-Prolabo), ethyl acetate (VWR-Prolabo), dimethyl sulfoxide (DMSO) (99\%, VWR-Prolabo), $\mathrm{SnCl}_{2} \cdot 2 \mathrm{H}_{2} \mathrm{O}$ (98\%, Alfa Aesar), benzoyl chloride (99\%, Sigma-Aldrich, St. Louis, MO, USA), methanol $\left(99.8 \%\right.$, Sigma-Aldrich), and deuterated dimethyl sulfoxide (DMSO- $\left.d_{6}\right)(99.80 \mathrm{D}$, VWR-Prolabo), $\mathrm{N}, \mathrm{N}$-dimethylacetamide (DMA) (99\%, Sigma-Aldrich. Vacuum distilled twice over phosphorous pentoxide and immediately stored over $4 \AA$ molecular sieves). $m$-phenylenediamine (MPD) (>99\%; Sigma-Aldrich. Purified by double vacuum sublimation). Isophthaloyl dichloride (ICL) ( $>99 \%$, Sigma-Aldrich. Purified by double crystallization upon dry heptane (99.9\%, VWR-Prolabo)).

\subsection{Measurements}

Nuclear Magnetic Resonance spectra (NMR) were obtained in a Varian Inova 400 spectrometer (Varian, Palo Alto, CA, USA) functioning at $400\left({ }^{1} \mathrm{H}\right)$ and $100.6\left({ }^{13} \mathrm{C}\right) \mathrm{MHz}$, using DMSO- $d_{6}$ as solvent. Infrared spectra (FTIR) were registered with a Jasco Spectrometer FT/IR-4200 FTIR (Jasco, Victoria, Canada) with an ATR-PRO410-S single reflection accessory. Fluorescence spectroscopy was carried out using a Hitachi spectrophotometer (F-7000 fluorescence, (Hitachi, Tokyo, Japan)), and Ultraviolet/Visible (UV/Vis) spectroscopy was performed in a Hitachi spectrophotometer (U-3900, (Hitachi, Tokyo, Japan)). High-resolution electrospray ionization mass spectra (ESI-HRMS) were obtained on a coupled liquid chromatographer-mass spectrometer (Agilent Infinity 1260-Agilent 6545, (Agilent, Santa Clara, CA. USA)). 
Thermal analysis was carried out by thermogravimetric measurements (TGA, TA Instrument Q50 TGA analyzer, (TA Instruments, New Castle, DE, USA)) using a $5 \mathrm{mg}$ sample under a nitrogen or oxygen atmosphere at a $10^{\circ} \mathrm{C} / \mathrm{min}$ scan rate. The LOI was calculated using the char yield mass percentage (CR) at $800{ }^{\circ} \mathrm{C}$ (obtained from the TGA measurements under a nitrogen atmosphere from the equation $\mathrm{LOI}=17.5+0.4 \times \mathrm{CR}$ (Van Krevelen, experimental equation [28]).

Differential Scanning Calorimetry (DSC) experiments were carried out to determine the thermal transitions of the copolyamides (DSC Q200, TA Instruments, New Castle, DE, USA); $\mathrm{N}_{2}$ atmosphere, flow rate $50 \mathrm{~mL} / \mathrm{min}$, about $15 \mathrm{mg}$ of sample.). The thermal analysis of the samples was performed as follows: First, a cycle was run to the samples to erase the thermal history consisting of 5 min of stabilization at $30{ }^{\circ} \mathrm{C}$, then, the samples were heated to $400{ }^{\circ} \mathrm{C}$ at a rate of $15{ }^{\circ} \mathrm{C}$ per minute and stabilized for $5 \mathrm{~min}$ at that temperature, then cooled down to $-80^{\circ} \mathrm{C}$. The second scan of up to $400{ }^{\circ} \mathrm{C}$ was performed at $15^{\circ} \mathrm{C}$ per minute.

The polymer solubility was evaluated with $10 \mathrm{mg}$ of the polymer and $1 \mathrm{~mL}$ of the solvent and stirring for $24 \mathrm{~h}$ at $20^{\circ} \mathrm{C}$. If a homogeneous solution is observed, the polymer is considered soluble at room temperature; otherwise, the system is heated to reflux for two hours, and the polymer is considered soluble on heating if a homogenous solution is formed. If no homogeneous solution is observed after that, the polymer is considered insoluble.

The polymer's inherent viscosity, $\eta_{i n h}$, was determined with a Canon-Fenske viscometer from a $0.5 \mathrm{~g} / \mathrm{dL}$ polymer concentration using sulfuric acid $(95 \%)$ as the solvent at $25 \pm 0.1{ }^{\circ} \mathrm{C}$. The intrinsic viscosity, $[\eta]$, was obtained measuring the $\eta_{i n h}$ at different polymer concentrations $(0.5,0.3,0.1$ and $0.05 \mathrm{~g} / \mathrm{dL}$ ) using the same solvent at $25 \pm 0.1^{\circ} \mathrm{C}$ and extrapolating to zero concentration. The number overage molecular mass $\left(\mathrm{M}_{\mathrm{w}}\right)$ was estimated from $[\eta]$ using the viscometric equation $[\eta]=\kappa \mathrm{M}_{\omega}{ }^{\alpha}$ with the constants of poly ( $m$-phenylene isophthalamide) ( $\kappa=0.00013 \mathrm{dL} / \mathrm{g} ; \alpha=0.84$ ) [29].

Water uptake measurements were performed gravimetrically. Dried samples (about $23 \mathrm{mg}$, dried at $60{ }^{\circ} \mathrm{C}$ for $24 \mathrm{~h}$ under vacuum and phosphorus pentoxide) were placed in a closed box at $20{ }^{\circ} \mathrm{C}$ having a relative humidity of $65 \%$ (provided by a saturated aqueous solution of $\mathrm{NaNO}_{2}$ ). The samples were weighed periodically until obtaining a constant mass. The water molecules per structural unit are calculated considering the weight of the structural unit and the water uptake. In copolymers, a hypothetical structural unit is calculated by considering the relative weight of the two structural units that comprise the copolyamides.

Films from copolyamides CP1 and CP2 were prepared by casting in DMA (solution-evaporation) with about $7 \%$ by polymer mass. Measurements of mechanical properties were performed with these untreated films with Shimazdu equipment (EZ Test Compact Table-Top Universal Tester, Shimadzu, Kyoto, Japan). The films were cut in $5 \times 40 \mathrm{~mm}$ strips, and the tests were performed with five samples of each film, averaging the data, with the following measurement conditions: $5 \mathrm{~mm} / \mathrm{min}$ extension rate, $9.44 \mathrm{~mm}$ gauge length.

The wide-angle $X$-ray diffraction patterns were acquired from powdered polyamides $(2 \mathrm{~h}$ in a SPEX SamplePrep 8000M Mill) using a Bruker D8 Discover Davinci X-ray diffractometer (40 kV, Bruker, Billlerica, MA. USA), Co as the radiation source, scan step size of 0.05 with a scan step time of $2 \mathrm{~s}$ for CP1 and $3 \mathrm{~s}$ for CP2).

\subsection{Synthesis of Intermediates, Monomers, and Models}

\subsubsection{Synthesis of Diamine D1 and Model Polyamide M1}

Synthesis of 2-bromo-1-(4-nitrophenyl)ethan-1-one (1): $\mathrm{Br}_{2}(100 \mathrm{mmol}, 5.13 \mathrm{~mL})$ was slowly added drop by drop to a solution of 4-nitroacetophenone $(100 \mathrm{mmol}, 16.5 \mathrm{~g})$ in diethyl ether $(300 \mathrm{~mL})$ at $0{ }^{\circ} \mathrm{C}$, and then stirred at room temperature for $2 \mathrm{~h}$. The solvent was evaporated under reduced pressure, and a solid was obtained (99\% yield). ${ }^{1} \mathrm{H}$ NMR $\left(400 \mathrm{MHz}, \mathrm{DMSO}-d_{6}, \delta\right)=8.16(\mathrm{~d}, J=9 \mathrm{~Hz}, 2 \mathrm{H}, \mathrm{Ph})$, $7.98(\mathrm{~d}, J=9.8 \mathrm{~Hz}, 2 \mathrm{H}, \mathrm{Ph}), 4.30\left(\mathrm{~s}, 2 \mathrm{H}, \mathrm{CH}_{2}\right)$. HRMS (ESI) calculated for $\left(\left[\mathrm{C}_{8} \mathrm{H}_{6} \mathrm{BrNO}_{3}\right]+\mathrm{H}\right)^{+}$: Not found. FT-IR [wavenumbers $\left(\mathrm{cm}^{-1}\right)$ ]: $v_{\mathrm{C}=\mathrm{O}}: 1698, v_{\mathrm{NO} 2}(\mathrm{As}, \mathrm{S}): 1513,1340$. 
Synthesis of 4,4'-bis(4-nitrophenyl)-2,2'-bithiazole (2): In a reduced pressure rounded-bottom flask dithiooxamide (10.23 mmol, $1.23 \mathrm{~g}$ ) was added to a solution of 2-bromo-1-(4-nitrophenyl)ethan-1-one 1 ( $20.5 \mathrm{mmol}, 5 \mathrm{~g})$ in ethanol $(100 \mathrm{~mL})$ and was stirred at $78^{\circ} \mathrm{C}$ overnight. The mixture was cooled to room temperature, and the brown solid formed was filtered and washed with methanol ( $86 \%$ yield). ${ }^{1} \mathrm{H}$ NMR $\left(400 \mathrm{MHz}\right.$, DMSO- $\left.d_{6}, \delta\right)=8.72(\mathrm{~s}, 2 \mathrm{H},=\mathrm{CH}), 8.41-8.27(\mathrm{~m}, 8 \mathrm{H}, \mathrm{Ph}) .{ }^{13} \mathrm{C}$ NMR was not possible due to the insolubility of the compound. HRMS (ESI) calculated for $\left(\left[\mathrm{C}_{18} \mathrm{H}_{10} \mathrm{~N}_{4} \mathrm{O}_{4} \mathrm{~S}_{2}\right]+\mathrm{H}\right)^{+}: 411.0216$; found: 411.0213. FT-IR [wavenumbers $\left(\mathrm{cm}^{-1}\right)$ ]: $v_{\text {Ar C-H }}: 3115, v_{\mathrm{C}-\mathrm{N}}: 1595, v_{\mathrm{NO} 2}(\mathrm{As}, \mathrm{S}): 1508,1336$.

Synthesis of the monomer, $4,4^{\prime}-\left(\left[2,2^{\prime}\right.\right.$-bithiazole $]-4,4^{\prime}$ diyl)dianiline (D1): To a solution of 4, $4^{\prime}$-bis(4-nitrophenyl)-2, $2^{\prime}$-bithiazole $2(16.5 \mathrm{mmol}, 6.95 \mathrm{~g})$ in ethanol $(55 \mathrm{~mL})$ was added $\mathrm{SnCl}_{2} \cdot 2 \mathrm{H}_{2} \mathrm{O}$ $(165 \mathrm{mmol}, 38.08 \mathrm{~g})$ in a reduced pressure rounded-bottom flask and heated at $70{ }^{\circ} \mathrm{C}$ for $4 \mathrm{~h}$. The mixture was poured into a combination of ice-water, and the $\mathrm{pH}$ was adjusted to 8-9 with $\mathrm{NaHCO}_{3}$. Ethyl acetate was used to extract the resulting mixture ( 3 times), and the combined organic layers were dried over $\mathrm{Na}_{2} \mathrm{SO}_{4}$ and concentrated at reduced pressure. The remaining residue was used without further purification (55\% yield). ${ }^{1} \mathrm{H}$ NMR $\left(400 \mathrm{MHz}\right.$, DMSO- $\left.d_{6}, \delta\right)=7.87(\mathrm{~s}, 2 \mathrm{H},=\mathrm{CH}), 7.70(\mathrm{~d}, 4 \mathrm{H}, J=8.6 \mathrm{~Hz}$, $\mathrm{Ph}), 6.66(\mathrm{~d}, 4 \mathrm{H}, J=8.6 \mathrm{~Hz}, \mathrm{Ph}), 5.36\left(\mathrm{~s}, 4 \mathrm{H}, \mathrm{NH}_{2}\right) .{ }^{13} \mathrm{C}$ NMR $\left(100.6 \mathrm{MHz}, \mathrm{DMSO}-d_{6}, \delta\right)=160.0$, 156.6, 149.2, 127.2, 121.4, 113.8, 111.9. HRMS (ESI) calculated for $\left(\left[\mathrm{C}_{18} \mathrm{H}_{14} \mathrm{~N}_{4} \mathrm{~S}_{2}\right]+\mathrm{H}\right)^{+}$: 351.0733; found: 351.0739. FT-IR [wavenumbers $\left(\mathrm{cm}^{-1}\right)$ ]: $v_{\mathrm{NH} 2}: 3412,3324, v_{\text {Ar C-H }}: 3095, v_{\mathrm{C}-\mathrm{N}}: 1601$.

Synthesis of $N, N^{\prime}$-([2,2'-bithiazole]-4, $\mathbf{4}^{\prime}$ diylbis(4,1-phenylene))dibenzamide (M1): Benzoyl chloride $(3.43 \mathrm{mmol}, 298.75 \mu \mathrm{L})$ was added portionwise to a solution of the previously prepared diamine D1 $(1.43 \mathrm{mmol}, 0.5 \mathrm{~g})$ in $\mathrm{N}, \mathrm{N}$-dimethylacetamide $(5 \mathrm{~mL})$ at $0{ }^{\circ} \mathrm{C}$ under nitrogen. After $30 \mathrm{~min}$ the resulting mixture was stirred at room temperature for an additional $4 \mathrm{~h}$. Then, the solution was poured into distilled water forming a yellowish solid which was filtered and washed with water yielding $81 \% .{ }^{1} \mathrm{H}$ NMR $\left(400 \mathrm{MHz}\right.$, DMSO- $\left.d_{6}, \delta\right)=10.42(\mathrm{~s}, 2 \mathrm{H}, \mathrm{NH}) ; 8.29(\mathrm{~s}, 2 \mathrm{H}, \mathrm{CH}) ; 8.12-7.85(\mathrm{~m}, 12 \mathrm{H}, \mathrm{Ph}) ; 7.66-7.49$ $(\mathrm{m}, 6 \mathrm{H}, \mathrm{Ph}) .{ }^{13} \mathrm{C}$ NMR $\left(100.6 \mathrm{MHz}\right.$, DMSO- $\left.d_{6}, \delta\right)=165.6 ; 160.4,155.3,139.5,134.8,131.7,128.70,128.41$, 127.70, 126.52, 120.45, 115.89. HRMS (ESI) calculated for $\left(\left[\mathrm{C}_{32} \mathrm{H}_{22} \mathrm{~N}_{4} \mathrm{O}_{2} \mathrm{~S}_{2}\right]+\mathrm{H}\right)^{+}$: 559.1257; found: 559.1254. FT-IR [wavenumbers $\left(\mathrm{cm}^{-1}\right)$ ]: $v_{\mathrm{NH}}: 3264, v_{\mathrm{Ar} \mathrm{C}-\mathrm{H}}: 3108, v_{\mathrm{C}=\mathrm{O}}: 1648$.

\subsubsection{Synthesis of Diamine D2 and Model Polyamide M2}

Synthesis of 2,5-bis(4-nitrophenyl)thiazolo[5,4-d]thiazole (3): Dithiooxamide (66.17 mmol, $7.95 \mathrm{~g}$ ) was added to a suspension of 4-nitrobenzaldehyde (132.34 mmol, $20 \mathrm{~g})$ in nitrobenzene $(130 \mathrm{~mL})$ and heated at $130{ }^{\circ} \mathrm{C}$ overnight. The resulting mixture was cooled to room temperature, and diethyl ether was added, forming a red solid which was filtered and washed with $\mathrm{Et}_{2} \mathrm{O}(61 \%)$ and employed in the next step without further purification. Due to the insolubility of the compound, NMR and HRMS were not possible to do. FT-IR [wavenumbers $\left(\mathrm{cm}^{-1}\right)$ ]: $v_{\mathrm{NO} 2}(\mathrm{As}, \mathrm{S}): 1513,1340$.

Synthesis of the monomer $4,4^{\prime}$-(thiazolo[5,4-d]thiazole-2,5-diyl)dianiline (D2): To a solution of 2,5-bis(4-nitrophenyl)thiazolo[5,4- $d$ ] thiazole $3(40.6 \mathrm{mmol}, 15.6 \mathrm{~g})$ in ethanol $(200 \mathrm{~mL})$ was added $\mathrm{SnCl}_{2} \cdot 2 \mathrm{H}_{2} \mathrm{O}(406 \mathrm{mmol}, 91.6 \mathrm{~g})$ in a reduced pressure rounded-bottom flask and heated at $70{ }^{\circ} \mathrm{C}$ for $4 \mathrm{~h}$. The mixture was poured into a combination of ice-water, and the $\mathrm{pH}$ was adjusted to $8-9$ with $\mathrm{NaHCO}_{3}$. Ethyl acetate was used to extract the resulting mixture (3 times), and the combined organic layers were dried over $\mathrm{Na}_{2} \mathrm{SO}_{4}$ and concentrated at reduced pressure. The remaining residue was pure and was used without further purification (28\% yield). ${ }^{1} \mathrm{H}$ NMR $\left(400 \mathrm{MHz}\right.$, DMSO- $\left.d_{6}, \delta\right)=7.65$ $(\mathrm{d}, 4 \mathrm{H}, \mathrm{J}=8.6 \mathrm{~Hz}, \mathrm{Ph}), 6.65(\mathrm{~d}, 4 \mathrm{H}, \mathrm{J}=8.6 \mathrm{~Hz}, \mathrm{Ph}), 5.83(\mathrm{~s}, 4 \mathrm{H}, \mathrm{NH}) .{ }^{13} \mathrm{C}$ NMR $\left(100.6 \mathrm{MHz}, \mathrm{DMSO}-d_{6}\right.$, $\delta)=168.75,152.04,148.31,127.86,121.24,114.13$. HRMS (ESI) calculated for $\left(\left[\mathrm{C}_{16} \mathrm{H}_{12} \mathrm{~N}_{4} \mathrm{~S}_{2}\right]+\mathrm{H}\right)^{+}$: 325.0576; found: 325.0578. FT-IR [wavenumbers $\left(\mathrm{cm}^{-1}\right)$ ]: $v_{\mathrm{NH} 2}: 3452,3324, v_{\mathrm{ArC}-\mathrm{H}}: 3311, v_{\mathrm{C}-\mathrm{N}}: 1598$.

Synthesis of $N, N^{\prime}$-(thiazolo[5,4- $d$ ] thiazole-2,5-diylbis(4,1-phenylene))dibenzamide (M2): Benzoyl chloride $(3.7 \mathrm{mmol}, 319.45 \mu \mathrm{L})$ was added portion-wise to a solution of the previously prepared diamine D2 $(1.54 \mathrm{mmol}, 0.5 \mathrm{~g})$ in $\mathrm{N}, \mathrm{N}$-dimethylacetamide $(5 \mathrm{~mL})$ at $0{ }^{\circ} \mathrm{C}$ under nitrogen atmosphere. After $30 \mathrm{~min}$, the resulting mixture was stirred at room temperature for another $4 \mathrm{~h}$. Then, the solution was 
poured into distilled water, forming a brown solid that was filtered and washed with water (yield: 78\%). ${ }^{1} \mathrm{H}$ NMR (400 MHz, DMSO- $\left.d_{6}, \delta\right)=10.42(\mathrm{~s}, 2 \mathrm{H}, \mathrm{NH}), 8.20-7.86(\mathrm{~m}, 12 \mathrm{H}, \mathrm{Ph}), 7.69-7.47(\mathrm{~m}, 6 \mathrm{H}$, $\mathrm{Ph}) .{ }^{13} \mathrm{C}$ NMR $\left(100.6 \mathrm{MHz}\right.$, DMSO- $\left.d_{6}, \delta\right)=$ Not possible due to the compound's solubility. HRMS (ESI) calculated for $\left(\left[\mathrm{C}_{30} \mathrm{H}_{20} \mathrm{~N}_{4} \mathrm{O}_{2} \mathrm{~S}_{2}\right]+\mathrm{Na}\right)^{+}: 555.0920$; found: 555.0917. FT-IR [wavenumbers $\left.\left(\mathrm{cm}^{-1}\right)\right]: v_{\mathrm{NH}}$ : $3340, v_{\mathrm{C}-\mathrm{N}}: 1523$.

\subsubsection{Synthesis of Copolyamides $\mathrm{CP} 1$ and $\mathrm{CP} 2$}

Synthesis of copolyamide CP1: Under nitrogen atmosphere in a three-necked flask with a mechanical stirrer was added $N, N$-dimethylacetamide $(4.5 \mathrm{~mL})$ at room temperature. Then, diamine $\mathbf{D} 1(0.443 \mathrm{mmol}$, $0.155 \mathrm{~g})$ and $m$-phenylenediamine $(3.989 \mathrm{mmol}, 0.431 \mathrm{~g})$ were added. The mixture was cooled to $0{ }^{\circ} \mathrm{C}$, and isophthaloyl dichloride $(4.43 \mathrm{mmol}, 0.9 \mathrm{~g}$ ) was added portion-wise. The reaction was reacted at $0{ }^{\circ} \mathrm{C}$ for $30 \mathrm{~min}$ and then heat to room temperature for another $4 \mathrm{~h}$. The solution was poured into distilled water rendering a swollen white precipitate that was filtered and washed with acetone (quantitative yield).

Synthesis of copolyamide CP2: Under nitrogen atmosphere in a three-necked flask with a mechanical stirrer was added $N, N$-dimethylacetamide $(4.5 \mathrm{~mL})$ at room temperature. Then, diamine $\mathbf{D} 2(0.443 \mathrm{mmol}$, $0.144 \mathrm{~g}$ ) and $\mathrm{m}$-phenylenediamine $(3.989 \mathrm{mmol}, 0.431 \mathrm{~g})$ were added. The mixture was cooled to $0{ }^{\circ} \mathrm{C}$, and isophthaloyl dichloride $(4.43 \mathrm{mmol}, 0.9 \mathrm{~g})$ was added portion-wise. The reaction was reacted at $0^{\circ} \mathrm{C}$ for $30 \mathrm{~min}$ and then heat at $50^{\circ} \mathrm{C}$ for another $4 \mathrm{~h}$. The solution was cooled to room temperature and poured into distilled water, rendering a yellow swollen polymer precipitate, filtered and washed with acetone (quantitative yield).

\section{Results and Discussion}

The technological world demands materials with higher mechanical and thermal performance. Accordingly, we describe herein the design, synthesis, characterization and evaluation of the properties of high-performance polymers for advanced applications, such as civil protection or aeronautics. We describe aromatic copolyamides with $10 \%$ of heteroaromatic groups (bithiazol or thiazolo[4,5-d]thiazol, $\mathbf{C P 1}$ and $\mathbf{C P 2}$, respectively) in the main chain of the polymer, which resulted in polymers with improved thermal stability and mechanical properties. It is known that aramids with small modifications in the structural units compared to poly ( $m$-phenylene isophthalamide) can provide enhanced characteristics to the polymer without penalizing their outstanding performance $[18,30]$.

To increase the thermal and mechanical characteristics of high-performance aromatic polyamides we have included in the aromatic main structure bithiazoles and thiazolo-thiazole moieties. These groups provide strong intermolecular interactions between $\mathrm{S}$ and $\mathrm{N}$ atoms, thus increasing the interchain interaction resulting in more efficient aggregation, higher cohesive energy, and higher mechanical and thermal properties [26].

To compare their performance, some of these synthesized polyamides' properties were compared with the properties of commercial poly( $m$-phenylene isophthalamide) synthesized as described in previous work [31] and the same conditions as CP1 and CP2.

\subsection{Synthesis and Characterization of the Monomer, the Model and the Polymers}

Diamines D1 and D2 were prepared following easy and are well-accepted reactions from the organic chemistry point of view (Schemes 1 and 2). The chemicals used in the synthesis of the monomers are commercial and cheap, and the reactions proceed in relatively good yields and with high purity, as verified by the NMR spectra. The chemical structure of all the intermediates and the monomers was confirmed by FTIR, ${ }^{1} \mathrm{H}$ and ${ }^{13} \mathrm{C}$, and HRMS. However, due to some of the intermediates' insolubility, it was not possible to perform the ${ }^{13} \mathrm{C}$ NMR in some cases, or even the HRMS for intermediates 1 and 3. Still, this was not a limiting fact since it was possible to characterize the rest of intermediates, monomers and model polyamides in the subsequent steps, confirming the products' structure. 


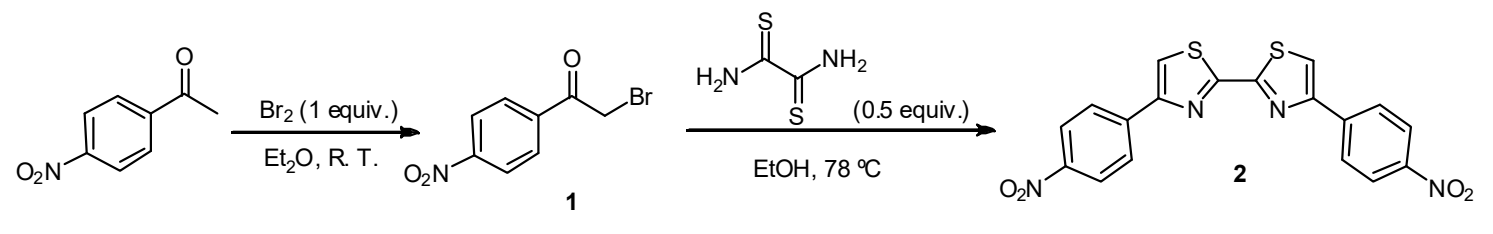<smiles>Cc1cccc(C(=O)Nc2ccc(-c3csc(-c4nc(-c5ccc(NC(=O)c6ccccc6)cc5)cs4)n3)cc2)c1</smiles>

Scheme 1. Synthesis of diamine D1 and model polyamide M1.<smiles>O=Cc1ccc([N+](=O)[O-])cc1</smiles>

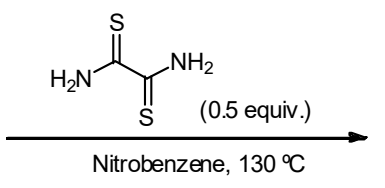<smiles>O=[N+]([O-])c1ccc(-c2nc3sc(-c4ccc([N+](=O)[O-])cc4)nc3s2)cc1</smiles>

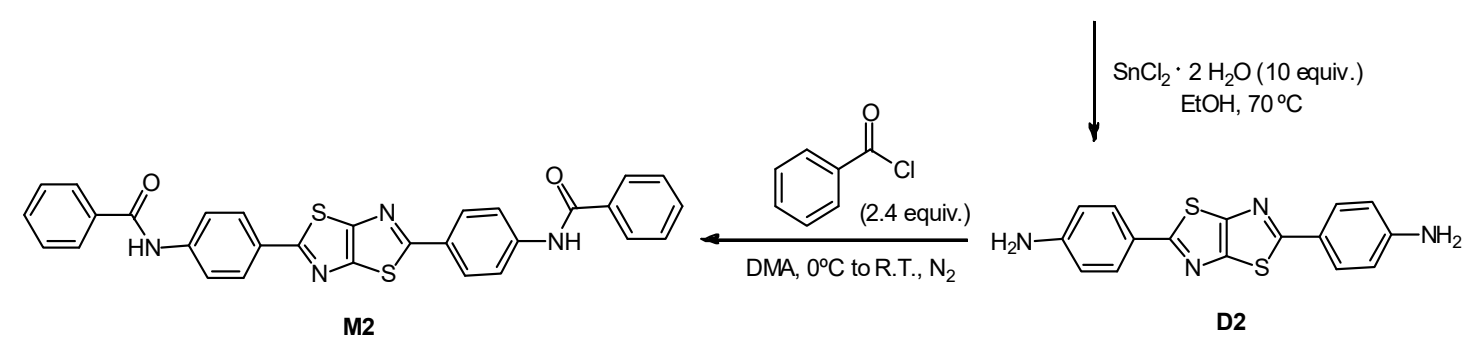

Scheme 2. Synthesis of diamine D2 and model polyamide M2.

Model polyamides M1 and M2 were synthesized before the polymer synthesis using polymerization conditions (Schemes 1 and 2). This strategy is recommended in the preparation of aramids to test the viability of the polyamide synthesis by characterizing the models, discard byproducts that would impair the preparation of the polymer, and thus their performance. Also, aramids are highly insoluble, and the preparation of model polyamides facilitates their characterization.

Copolyamide CP1 was prepared following the conventional procedure from $m$-phenylene diamine and isophthaloyl dichloride (commercial monomers), and diamine D1 in DMA at $0{ }^{\circ} \mathrm{C}$ and then heating at room temperature (Scheme 3). $\mathbf{C P 2}$ was prepared similarly from the two commercial monomers and diamine $\mathbf{D} 2$, but this time it was necessary to heat the mixture to $50{ }^{\circ} \mathrm{C}$ due to the insolubility of the diamine. The structure of the polyamides is shown in Scheme 3. Their inherent viscosities and molecular masses are depicted in Table $1 .{ }^{1} \mathrm{H}$ and ${ }^{13} \mathrm{C}$ NMR spectra are consistent with the copolyamides structure, and show a high degree of polycondensation, confirmed by the molecular mass of the polyamides ( $3.4 \times 10^{4}$ and $3.3 \times 10^{4}$ for $\mathbf{C P 1}$ and $\mathbf{C P 2}$, respectively) obtained from the values of intrinsic viscosities using the Mark-Houwink-Sakurada (MKS) equation [28]. 
<smiles></smiles><smiles>[Y]CC(C)(C)C(=O)c1cccc(C(=O)Nc2ccc(-c3csc(-c4nc(-c5ccc(NC(C)C)cc5)cs4)n3)cc2)c1</smiles><smiles>[Y][Y4]#[Y6]=O</smiles>

Scheme 3. Synthesis of copolyamides CP1 and CP2.

Table 1. Inherent viscosity, intrinsic viscosity, and molecular mass of polymers CP1 and CP2.

\begin{tabular}{cccc}
\hline Copolymer & $\eta_{\text {inh }}{ }^{\text {a }}(\mathrm{dL} / \mathrm{g})$ & {$[\eta]^{\mathbf{b}}(\mathrm{dL} / \mathrm{g})$} & $\mathbf{M}_{\mathbf{w}}{ }^{\mathrm{c}}$ \\
\hline CP1 & 0.72 & 0.83 & $3.4 \times 10^{4}$ \\
CP2 & 0.80 & 0.82 & $3.3 \times 10^{4}$
\end{tabular}

a $0.5 \mathrm{~g} / \mathrm{dL}$ solution in $\mathrm{H}_{2} \mathrm{SO}_{4} \cdot{ }^{\mathrm{b}} 0.5,0.3,0.1$ and $0.05 \mathrm{~g} / \mathrm{dL}$ solution in $\mathrm{H}_{2} \mathrm{SO}_{4} \cdot{ }^{\mathrm{c}}$ From $[\eta]$ and the MKS equation and viscometric constants of poly $(m$-phenylene isophthalamide $(\kappa=0.00013 \mathrm{dL} / \mathrm{g} ; \alpha=0.84)$ [29].

We prepared polymer films from these two copolyamides to evaluate their mechanical and optical performance following a casting procedure, using about $7 \%$ (mass/volume) solutions of the copolyamides in DMA.

\subsection{Properties of the Polymers}

\subsubsection{Water Uptake and Solubility}

Table 2 shows the solubilities of the polyamides and the models. Aramids are soluble only in polar aprotic solvents, and CP1 and CP2 show low solubility (lower than the solubility of commercial poly ( $m$-phenylene isophthalamide) $)$ in these solvents, due to the rigid and ordered structure derived from the heteroaromatic rings of the main chain coming from the $\mathrm{N}$ and $\mathrm{S}$ interactions of the heteroaromatic moieties of the main chain [26]. Also, model polyamides show low solubility in polar aprotic solvents and are insoluble in other organic solvents. 
Table 2. Water uptake and solubility of aromatic polyamides and the models.

\begin{tabular}{|c|c|c|c|c|c|c|c|}
\hline \multirow{2}{*}{$\begin{array}{l}\text { Model or } \\
\text { Polymer }\end{array}$} & \multicolumn{2}{|c|}{ Water Uptake ${ }^{a}$} & \multicolumn{5}{|c|}{ Solubility ${ }^{b}$} \\
\hline & Mass (\%) & $\begin{array}{l}\text { Water Molecules Per } \\
\text { Structural Unit }{ }^{c}\end{array}$ & DMA & DMF & DMSO & NMP & $\begin{array}{c}\text { EtOH, THF, Acetone, } \\
\mathrm{CH}_{2} \mathrm{Cl}_{2}, \mathrm{CHCl}_{3}\end{array}$ \\
\hline M1 & & -- & ++ & + & + & ++ & - \\
\hline M2 & & -- & +- & +- & + & + & - \\
\hline CP1 & 7.1 & 0.98 & ++ & ++ & ++ & ++ & - \\
\hline CP2 & 7.2 & 1.02 & ++ & +- & + & ++ & - \\
\hline Reference $^{\mathrm{d}}$ & 5.2 & 1.2 & ++ & ++ & ++ & ++ & - \\
\hline
\end{tabular}

The polar groups of an organic molecule determine its hydrophilicity or hydrophobicity. The amide linkage of aromatic polyamides is highly polar, and thus it absorbs water from the environment. Water sorption in aramids enhances some properties while prejudices others. It weakens the amide-amide interactions, lowers the thermal transitions, the mechanical and thermal properties, and impairs electrical insulation. On the other hand, the high water uptake is desirable for applications such as membranes for water desalination. Commercial poly ( $m$-phenylene isophthalamide) absorbs $5.2 \%$ of water, and $\mathbf{C P 1}$ and $\mathbf{C P 2}$ show comparable water sorption, of around 7\% (Table 2). Considering the number of water molecules of water per structural unit, the values of CP1 and CP2 are slightly lower than the 1.2 molecules of water of poly ( $m$-phenylene isophthalamide).

\subsubsection{Mechanical Properties of the Copolyamides}

The results from the measurements of the mechanical properties of the films from CP1 and CP2 were higher than those found for the lab-made poly ( $m$-phenylene isophthalamide) films prepared by casting in the same conditions (Table 3 and Supplementary Materials, Section S6). This improvement in the moduli and the tensile strength probably originates from the additional interchain interactions derived from the presence of $\mathrm{S}$ and $\mathrm{N}$ atoms in the structures of the new monomers, as previously commented. At this point, it should be considered that the mechanical properties have been calculated using films obtained by casting without post-thermal and mechanical treatment. However, the differences with commercial aramids are relevant because we have obtained and measured the properties with respect to the reference aramid in the same conditions.

Table 3. Mechanical properties of CP1 and CP2 films.

\begin{tabular}{ccc}
\hline Polymer & Young's Modulus (GPa) & Tensile Strength (MPa) \\
\hline CP1 & 2.2 & 77 \\
CP2 ${ }^{\text {b }}$ & 1.9 & 70 \\
Reference $^{\text {a }}$ & 1.4 & 63
\end{tabular}

a Poly ( $m$-phenylene isophthalamide). ${ }^{\mathrm{b}} \mathbf{C P 2}$ mechanical properties values are lower than expected probably because of the difficulties in preparing the films by casting due to the lower solubility of the polymer compared to CP1.

\subsubsection{Thermal Properties of the Copolyamides}

The thermal performance of the polyamides was tested by DSC and TGA analyses. The TGA measurement results are depicted in Table 4 and Supplementary Materials, Section S7). 5\% and 10\% mass loss temperatures $\left(T_{5}\right.$ and $\left.T_{10}\right)$ of the copolyamides are over $445^{\circ} \mathrm{C}$, and $469^{\circ} \mathrm{C}$, respectively, both in nitrogen and in air. These are significantly higher than that of commercial poly $(m$-phenylene isophthalamide) $\left(419{ }^{\circ} \mathrm{C}\right.$ and $\left.432{ }^{\circ} \mathrm{C}\right)$.

The char yields are also relevant parameters. These were over $57 \%$ at $800{ }^{\circ} \mathrm{C}$ in nitrogen. The char yield at a given temperature is associated with the polymer's thermal behavior, and it is used to evaluate the limiting oxygen index (LOI, Van Krevelen equation [27]). The polyamides showed LOI values over 40 , meaning that they can be considered self-extinguishing polymers, as air contains 
approximately $21 \%$ of oxygen. The LOI values of CP1 and CP2 (40 and 41, respectively) are also improved compared to commercial poly( $m$-phenylene isophthalamide) (LOI value of 38).

Table 4. Thermal TGA data of the polymers in an inert $\left(\mathrm{N}_{2}\right)$ and an oxidizing (synthetic air) atmosphere.

\begin{tabular}{|c|c|c|c|c|c|c|c|c|}
\hline \multirow{2}{*}{ Polymer } & \multicolumn{3}{|c|}{ Under Nitrogen } & \multicolumn{3}{|c|}{ Under Oxygen (Synthetic Air) } & \multirow{2}{*}{ LOI $^{c}$} & \multirow{2}{*}{$T_{g}\left({ }^{\circ} \mathrm{C}\right)$} \\
\hline & $\mathrm{T}_{5}{ }^{\mathrm{a}}\left({ }^{\circ} \mathrm{C}\right)$ & $\mathrm{T}_{10}{ }^{\mathrm{b}}\left({ }^{\circ} \mathrm{C}\right)$ & CR (\%) & $\mathrm{T}_{5}{ }^{\mathrm{a}}\left({ }^{\circ} \mathrm{C}\right)$ & $\mathrm{T}_{10}{ }^{\mathrm{b}}\left({ }^{\circ} \mathrm{C}\right)$ & CR (\%) & & \\
\hline CP1 & 449 & 470 & 57 & 451 & 483 & 0.7 & 40 & 280 \\
\hline CP2 & 445 & 469 & 58 & 446 & 478 & 0.8 & 41 & 286 \\
\hline Reference $^{\mathrm{d}}$ & 432 & 452 & 50 & 419 & 445 & 9 & 38 & 273 \\
\hline
\end{tabular}

On the other hand, the $T_{\mathrm{g}}$ is higher for the new copolyamides than for the commercial poly(m-phenylene isophthalamide) (Table 4$)$, showing the positive impact of the heterocycle in the structural unit, the rigidity of the chain derived from the rigidity of the monomer in the case of CP2, and the extra interchain interactions (amide/heterocycle, heterocycle/heterocycle) compared to conventional poly( $m$-phenylene isophthalamide).

\subsubsection{Wide Angle Powder X-ray Scattering}

The crystallinity of both polyamides was tested, and they displayed an amorphous pattern (Figure 1). The average molecular interchain spacing $(<R>)$ can be calculated [32] from the maximum $\left(\theta_{\max }\right)$ of the $x$-ray diffraction for amorphous polymers, using the equation $<R>=5 / 8\left(\lambda / \sin \theta_{\max }\right)$. The average distance of the polymer chains in the amorphous region was estimated to be $4.43 \AA$ in the first amorphous region. In contrast, it is $4.69 \AA$ for commercial poly( $m$-phenylene isophthalamide) (calculated from the work of Lee et al. Figure 1 [33]). The difference in distances agrees with the proposed higher interchain interaction provided by the heteroaromatic moieties in the newly reported aramids.

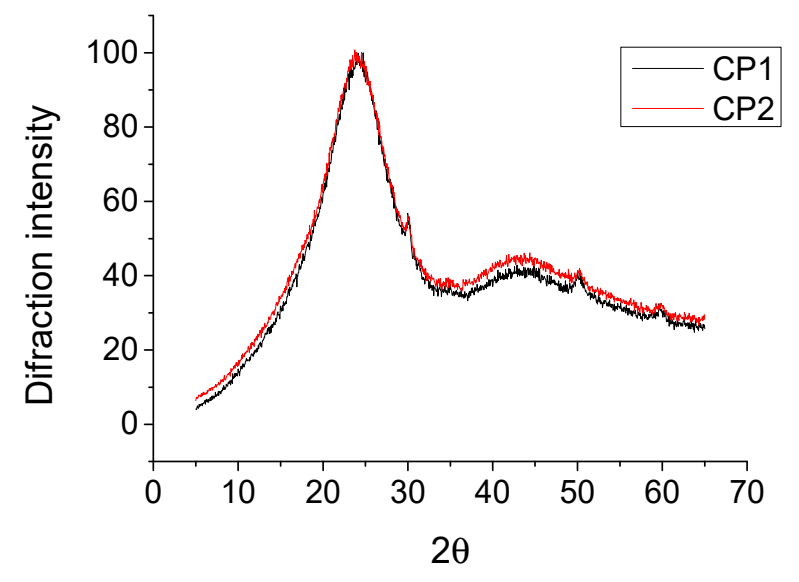

Figure 1. Powder X-ray scattering of CP1 and CP2.

\subsubsection{Optical Properties}

\section{Luminescence Properties}

The photoluminescence properties of the films obtained from the copolyamides were tested. Fluorescence spectra of CP1 and CP2 films were obtained applying different excitation wavelengths to test their emission behavior. Emission fluorescence was observed when the films were irradiated at $370 \mathrm{~nm}$, showing maximum emission bands at $485 \mathrm{~nm}$ for CP1 and $505 \mathrm{~nm}$ for CP2. Figure 2 shows the fluorescence emission (a) and absorption spectra (b) of CP1 and CP2 films. 


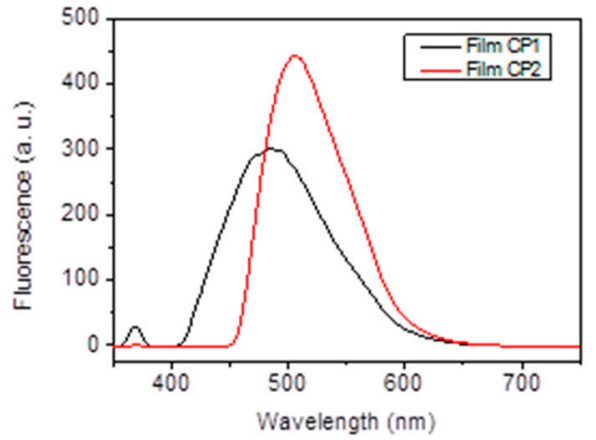

(a)

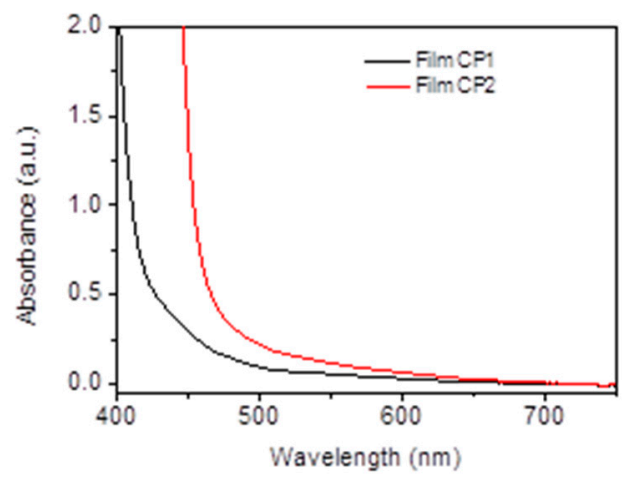

(b)

Figure 2. (a) Emission spectra of films of CP1 and CP2 with under an excitation wavelength of $\lambda_{\mathrm{ex}}=370 \mathrm{~nm}$. (maximum emission $\lambda_{\mathrm{em}}$ Film CP1 $=485 \mathrm{~nm}$. $\lambda_{\mathrm{em}}$ Film CP2 $=505 \mathrm{~nm}$ ). (b) Absorbance spectra of CP1 and CP2 films.

The quantum yield was calculated for model polyamides M1 and M2 in DMA solution, using a quinine solution in $0.05 \mathrm{M}$ sulfuric acid as the fluorescence pattern, and an excitation wavelength of $370 \mathrm{~nm}$. The results obtained show that model polyamide $\mathbf{M} 2$ has a considerably higher quantum yield $\left(\varnothing_{370}=0.225\right)$ than $\mathbf{M 1}\left(\varnothing_{370}=0.028\right)$. The quantum yield of $\mathbf{M} 2$ was higher than other values reported for some fluorescent aromatic polyamides for sensory applications $[34,35]$. However, the quantum yields achieved are still too low for fluorescent materials to be used in light-emitting applications $[2,36]$.

\section{CIE 1931}

The color spectrum visible to the average human, the perceived colors, can be represented following a numerical model, the CIE color model, where the coordinates $x$ and $y$ specify the colors in practice. So they were evaluated for the model polyamides. Figure 3 shows the CIE chromaticity coordinates of $\mathbf{M 1}$ and M2, calculated from the fluorescence spectra using CIE 1931 color-matching functions $(x$ and $y)$ [37]. The CIE coordinates were: $\mathbf{M 1}\left(\mathrm{x}, \mathrm{y} ; \lambda_{\mathrm{exc}}\right):(0.15,0.12 ; 370 \mathrm{~nm}) ; \mathbf{M} 2\left(\mathrm{x}, \mathrm{y} ; \lambda_{\mathrm{exc}}\right)$ : $(0.15,0.10 ; 370 \mathrm{~nm})[38]$.

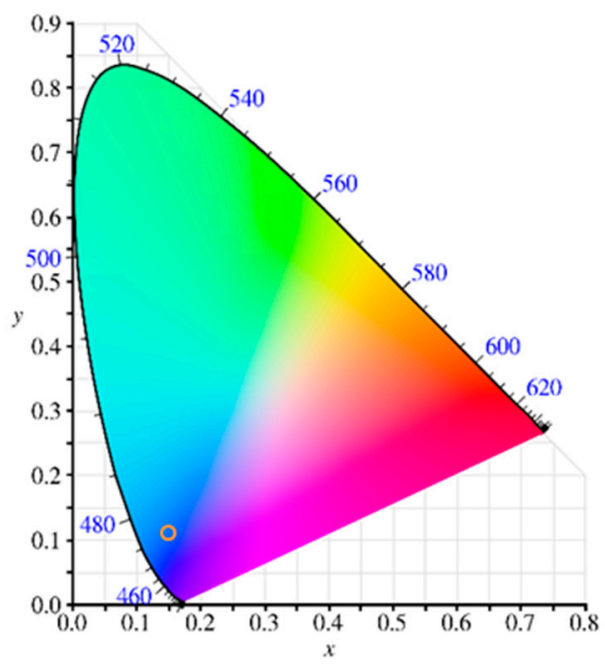

(a)

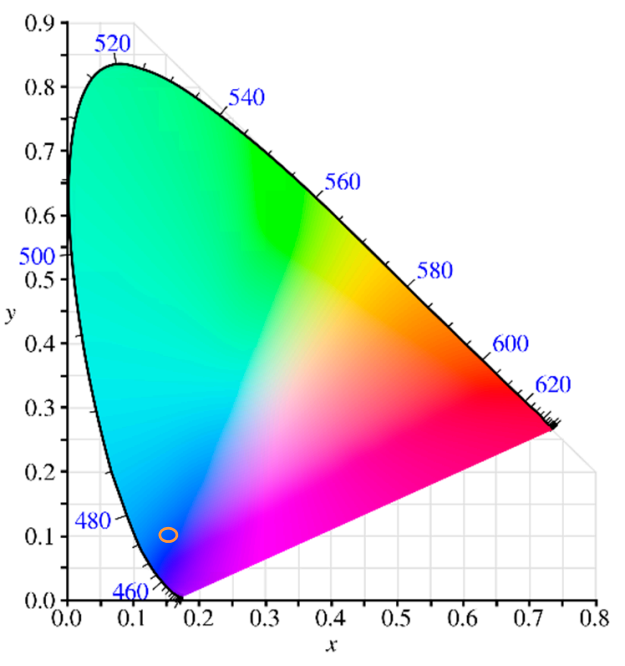

(b)

Figure 3. CIE chromaticity coordinates of a) $\mathbf{M} 1(x=0.15, y=0.12)$ and $\mathbf{b}) \mathbf{M} 2(x=0.15, y=0.10)$. $\lambda_{\mathrm{ex}}=370 \mathrm{~nm}$. 


\section{Conclusions}

In short, we have successfully prepared two fluorescent copolyamides containing bithiazole and thiazolo-thiazole groups in their main chain, obtaining aramids with improved thermal and mechanical properties compared to commercial aramids, as a result of the additional interchain interactions. Therefore, the modification of the structure of commercial aramids by introducing heteroaromatic moieties brings new characteristics to commercial high-performance polymers, opening new application fields. The newly synthesized aramids could be used for advanced applications, such as biomedicine, fluorescent chemosensors, photovoltaics or optoelectronic devices, and advanced fibers and composites.

Supplementary Materials: The following are available online at http:/www.mdpi.com/2073-4360/12/8/1793/s1, Supplementary information contains the FTIR, ${ }^{1} \mathrm{H}$ NMR, and ${ }^{13} \mathrm{C}$ NMR of the intermediates, monomers, model polyamides and polymers, and thermal and mechanical characterization of the polymers.

Author Contributions: Conceptualization, M.T.-L., A.M.S., A.M. (Asunción Muñoz), F.C.G., and J.M.G.; formal analysis, A.M.S., A.M. (Aranzazu Mendía), A.M. (Asunción Muñoz); funding acquisition, J.M.G., and F.C.G.; investigation, M.T.-L., A.M.S., A.M. (Aranzazu Mendía), F.C.G.; methodology, M.T.-L., A.M.S., F.C.G., and J.M.G.; project administration, F.C.G., and J.M.G.; supervision, F.C.G., and M.T.-L.; writing-original draft, M.T.-L., A.M.S., A.M. (Asunción Muñoz), A.M. (Aranzazu Mendía), and J.M.G. All authors have read and agreed to the published version of the manuscript.

Funding: Financial support provided by Fondo Europeo de Desarrollo Regional and both the Spanish Ministerio de Economía, Industria y Competitividad (MAT2017-84501-R) and the Consejería de Educación, Junta de Castilla y León (BU306P18) is gratefully acknowledged. M.T.L. also thankfully acknowledges the Spanish Ministerio de Ciencia e Innovación (PID2019-108583RJ-I00/AEI/10.13039/501100011033).

Conflicts of Interest: The authors declare that there is no conflict of interest.

\section{References}

1. US Federal Trade Commission (FTC). Rules and regulations under the textile fiber products identification act. Part 303.7 (Generic names and definitions for manufactured fibers); US Federal Trade Commission (FTC): Washington, DC, USA, 2006.

2. Reglero Ruiz, J.A.; Trigo-López, M.; García, F.C.; García, J.M. Functional Aromatic Polyamides. Polymers (Basel) 2017, 9, 414. [CrossRef] [PubMed]

3. Bandaru, A.K.; Chouhan, H.; Bhatnagar, N. High strain rate compression testing of intra-ply and inter-ply hybrid thermoplastic composites reinforced with Kevlar/basalt fibers. Polym. Test. 2020, 84, 106407. [CrossRef]

4. Oh, J.-H.; Bae, J.-H.; Kim, J.-H.; Lee, C.-S.; Lee, J.-M. Effects of Kevlar pulp on the enhancement of cryogenic mechanical properties of polyurethane foam. Polym. Test. 2019, 80, 106093. [CrossRef]

5. Yang, C.Q.; He, Q.; Lyon, R.E.; Hu, Y. Investigation of the flammability of different textile fabrics using micro-scale combustion calorimetry. Polym. Degrad. Stab. 2010, 95, 108-115. [CrossRef]

6. Aharoni, S.M.; Curran, S.A.; Murthy, N.S. Poly(p-phenyleneterephthalamide) and poly(m-phenyleneisophthalamide): Positional isomers with partial miscibility. Macromolecules 1992, 25, 4431-4436. [CrossRef]

7. Jiang, J.-W.; Pei, X.-L.; Sheng, S.-R.; Wu, X.-Y.; Liu, X.-L.; Song, C.-S. Novel soluble fluorine-containing polyamides derived from 2-(4-trifluoromethylphenoxy)terephthalic acid and trifluoromethyl-substituted aromatic bis(ether amine)s. Polym. Bull. 2011, 67, 263-274. [CrossRef]

8. Zhou, Y.-T.; Huang, Z.-Z.; Song, C.; Tang, C.-C.; Liu, X.-L.; Sheng, S.-R. New fluorinated aromatic polyamides based on N,N -bis(4-carboxyphenyl)-4-trifluoromethylaniline. High Perform. Polym. 2019, 31, 613-622. [CrossRef]

9. Jiang, J.; Huang, S.; Liu, Y.; Sheng, S.; Huang, Z.; Song, C. Synthesis and Characterization of New Soluble Polyamides from 9,9-Bis[4-(chloroformylphenoxy)phenyl]xanthene and Various Aromatic Diamines. Chin. J. Chem. 2010, 28, 102-110. [CrossRef]

10. Rafiee, Z.; Mallakpour, S. Synthesis and properties of novel brominated chiral polyamides derived from 5-[4-(2-tetrabromophthalimidylpropanoylamino)benzoylamino]isophthalic acid and aromatic diamines. Polym. Bull. 2016, 73, 1951-1964. [CrossRef] 
11. Yu, G.; Li, B.; Liu, J.; Wu, S.; Tan, H.; Pan, C.; Jian, X. Novel thermally stable and organosoluble aromatic polyamides with main chain phenyl-1,3,5-triazine moieties. Polym. Degrad. Stab. 2012, 97, 1807-1814. [CrossRef]

12. Chen, J.-C.; Rajendran, K.; Huang, S.-W.; Chang, H.-W. Synthesis and characterization of aromatic polyamides derived from various derivatives of 4,4'-oxydianiline. J. Polym. Res. 2011, 18, 1693-1703. [CrossRef]

13. Tan, J.; Wang, C.; Peng, W.; Li, G.; Jiang, J.-M. Synthesis, characterization, and properties of novel aromatic polyamides containing phthalazinone moiety. Polym. Bull. 2009, 62, 195-207. [CrossRef]

14. Bera, D.; Dasgupta, B.; Chatterjee, S.; Maji, S.; Banerjee, S. Synthesis, characterization, and properties of semifluorinated organo-soluble new aromatic polyamides. Polym. Adv. Technol. 2012, 23, 77-84. [CrossRef]

15. Yu, Y.; Cai, M.; Zhang, Y. Study on synthesis of novel soluble aromatic polyamides with pendant cyano groups. Polym. Bull. 2010, 65, 309-318. [CrossRef]

16. Zou, F.; Wen, H.; Yan, T.; Cai, M. Synthesis and properties of novel soluble aromatic polyamides containing 4-aryl-2,6-diphenylpyridine moieties and pendant fluorinated phenoxy groups. J. Polym. Res. 2016, 23, 225. [CrossRef]

17. Carja, I.-D.; Hamciuc, C.; Hamciuc, E.; Vlad-Bubulac, T.; Lisa, G. New highly thermostable aromatic polyamides with pendant phthalonitrile groups. Macromol. Res. 2012, 20, 1011-1020. [CrossRef]

18. Trigo-López, M.; Pablos, J.L.; García, F.C.; Serna, F.; García, J.M. Functional aramids: Aromatic polyamides with reactive azido and amino groups in the pendant structure. J. Polym. Sci. Part A Polym. Chem. 2014, 52, 1469-1477. [CrossRef]

19. Chen, H.-J.; Wang, W.-L.; Wang, G.-F.; Shi, L.-P.; Gu, M.; Ren, Y.-D.; Hou, L.-F.; He, P.-L.; Zhu, F.-H.; Zhong, X.-G.; et al. Rational Design and Synthesis of 2,2-Bisheterocycle Tandem Derivatives as Non-Nucleoside Hepatitis B Virus Inhibitors. ChemMedChem 2008, 3, 1316-1321. [CrossRef]

20. Mourer, M.; Psychogios, N.; Laumond, G.; Aubertin, A.-M.; Regnouf-de-Vains, J.-B. Synthesis and anti-HIV evaluation of water-soluble calixarene-based bithiazolyl podands. Bioorg. Med. Chem. 2010, 18, 36-45. [CrossRef]

21. Zhou, Z.; Sun, W.; Tang, J.; Shen, Z. Synthesis of novel copolymers containing tri(ethylene oxide) segments and bithiazole rings on the backbone and magnetic properties of their complexes. Polymer (Guildf) 2006, 47, 6280-6284. [CrossRef]

22. Geng, J.; Liu, Y.; Li, J.; Yin, G.; Huang, W.; Wang, R.; Quan, Y. A ratiometric fluorescent probe for ferric ion based on a 2,2'-bithiazole derivative and its biological applications. Sens. Actuators B Chem. 2016, 222, 612-617. [CrossRef]

23. Guo, X.; Zhang, M.; Huo, L.; Cui, C.; Wu, Y.; Hou, J.; Li, Y. Poly(thieno[3,2- b ]thiophene- alt -bithiazole): A D-A Copolymer Donor Showing Improved Photovoltaic Performance with Indene-C 60 Bisadduct Acceptor. Macromolecules 2012, 45, 6930-6937. [CrossRef]

24. Oniwa, K.; Kikuchi, H.; Kanagasekaran, T.; Shimotani, H.; Ikeda, S.; Asao, N.; Yamamoto, Y.; Tanigaki, K.; Jin, T. Biphenyl end-capped bithiazole co-oligomers for high performance organic thin film field effect transistors. Chem. Commun. 2016, 52, 4926-4929. [CrossRef] [PubMed]

25. Zahradník, P.; Magdolen, P.; Zahradník, P. Thiazolo[4,5- $d$ ] thiazole-A new domain for potential optoelectronic application. Tetrahedron Lett. 2010, 51, 5819-5821. [CrossRef]

26. Bevk, D.; Marin, L.; Lutsen, L.; Vanderzande, D.; Maes, W. Thiazolo[5,4- $d]$ thiazoles—Promising building blocks in the synthesis of semiconductors for plastic electronics. RSC Adv. 2013, 3, 11418. [CrossRef]

27. Kuwabara, J.; Kuramochi, M.; Liu, S.; Yasuda, T.; Kanbara, T. Direct arylation polycondensation for the synthesis of bithiazole-based conjugated polymers and their physical properties. Polym. J. 2017, 49, 123-131. [CrossRef]

28. Van Krevelen, D.W.; te Nijenhuis, K. Properties of Polymers, 4th ed.; Elsevier Science: Amsterdam, The Netherlands, 2009; ISBN 9780080548197.

29. Harwood, D.; Aoki, H.; Lee, Y.-D.; Fellers, J.F.; White, J.L. Solution and rheological properties of poly(m-phenyleneisophthalamide) in dimethylacetamide/LiCl. J. Appl. Polym. Sci. 1979, 23, 2155-2168. [CrossRef]

30. Trigo-López, M.; Miguel-Ortega, Á.; Vallejos, S.; Muñoz, A.; Izquierdo, D.; Colina, Á.; García, F.C.; García, J.M. Intrinsically colored wholly aromatic polyamides (aramids). Dye. Pigment. 2015, 122, 177-183. [CrossRef]

31. Trigo-López, M.; Barrio-Manso, J.L.; Serna, F.; García, F.C.; García, J.M. Crosslinked Aromatic Polyamides: A Further Step in High-Performance Materials. Macromol. Chem. Phys. 2013, 214, 2223-2231. [CrossRef] 
32. Halasa, A.F.; Wathen, G.D.; Hsu, W.L.; Matrana, B.A.; Massie, J.M. Relationship between interchain spacing of amorphous polymers and blend miscibility as determined by wide-angle X-ray scattering. J. Appl. Polym. Sci. 1991, 43, 183-190. [CrossRef]

33. Kim, J.-Y.; Jung, J.-W.; Kim, S.-S.; Lee, J.-W. m-Aramid Films in Diverse Coagulants. Text. Color. Finish. 2009, 21, 63-67. [CrossRef]

34. Barrio-Manso, J.L.; Calvo, P.; García, F.C.; Pablos, J.L.; Torroba, T.; García, J.M. Functional fluorescent aramids: Aromatic polyamides containing a dipicolinic acid derivative as luminescent converters and sensory materials for the fluorescence detection and quantification of $\mathrm{Cr}(\mathrm{vi}), \mathrm{Fe}(\mathrm{iii})$ and $\mathrm{Cu}(\mathrm{ii})$. Polym. Chem. 2013, 4, 4256. [CrossRef]

35. Gómez-Valdemoro, A.; Martínez-Máñez, R.; Sancenón, F.; García, F.C.; García, J.M. Functional Aromatic Polyethers: Polymers with Tunable Chromogenic and Fluorogenic Properties. Macromolecules 2010, 43, 7111-7121. [CrossRef]

36. Miguel-Ortega, Á.; Trigo-López, M.; García, F.C.; Reglero, J.A.; Martínez-Alonso, M.; Espino, G.; García, J.M. Hybrid aramids, Ir(III)-functionalized aromatic polyamides. Eur. Polym. J. 2017, 95, 119-126. [CrossRef]

37. International Commission on Illumination. The Colour Matching Parameters were Downloaded for Free from the CIE Web Page. Available online: http://files.cie.co.at/204.xls (accessed on 8 February 2020).

38. Ohta, N.; Robertson, A.R. CIE Standard Colorimetric System. In Colorimetry. Fundamentals and Applications; John Wiley \& Sons, Ltd.: Chichester, UK, 2005; pp. 92-96.

(C) 2020 by the authors. Licensee MDPI, Basel, Switzerland. This article is an open access article distributed under the terms and conditions of the Creative Commons Attribution (CC BY) license (http://creativecommons.org/licenses/by/4.0/). 